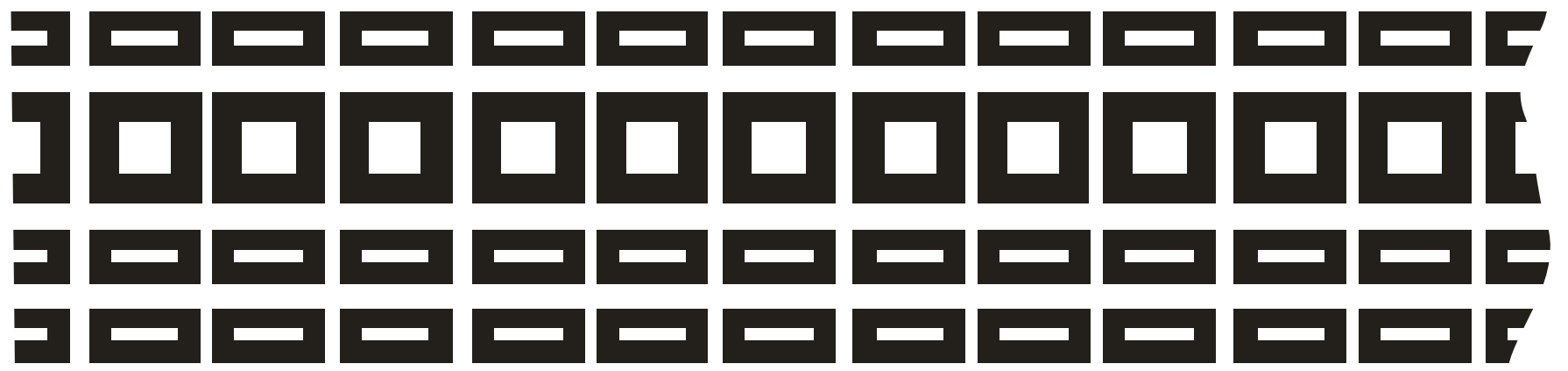

\title{
Retratos pungentes de populacoes periféricas: Marshall Berman e Helena Viramontes
}

\author{
Lidia da Cruz \\ Cordeiro Moreira
}

\section{Resumo}

A construção da Via Expressa do Bronx, em Nova Iorque, e do complexo de Vias Expressas de East Los Angeles, em Los Angeles, contribuíram imensamente para a deterioração dos bairros periféricos que cortaram em meados do século XX. Parte de suas populações - a maior parte das quais pertencia a minorias, principalmente judeus em Nova Iorque e latinos em Los Angeles - foi repentinamente desenraizada e aqueles que permaneceram tiveram que aprender a viver na nova paisagem. Este artigo enfoca Tudo que é sólido desmancha no ar, do filósofo nova-iorquino Marshall Berman, e Their Dogs Came With Them e "Neighbors", da escritora chicana Helena María Viramontes. Essas obras, aparentemente tão distantes, pintam retratos pungentes do deslocamento dessas populações periféricas, separadas por um país inteiro, mas ainda assim semelhantes em sua condição.

Palavras-chave: bairros periféricos; deslocamento populacional; Marshall Berman; Helena María Viramontes.

\section{Abstract}

The construction of the Cross-Bronx Expressway, in New York, and of the East Los Angeles Interchange complex, in Los Angeles, contributed im- 
mensely to the deterioration of the peripheral neighborhoods they cut through in the middle of the twentieth century. Part of their populations - most of which belonged to minorities, mainly Jewish people in New York and Latinos in Los Angeles - was suddenly uprooted, and those who remained had to learn to live in the new landscape. This article focuses on All That Is Solid Melts Into Air, by philosopher Marshall Berman, and Their Dogs Came With Them and "Neighbors," by Chicana writer Helena María Viramontes. These works, apparently so distant from each other, paint poignant portraits of the displacement of these peripheral populations, separated by an entire country, and yet so similar in their plight.

Keywords: peripheral neighborhoods; displacement; Marshall Berman; Helena María Viramontes

\begin{abstract}
Se você alguma vez já se perguntou se estava no Inferno, então, você experimentou um dilema espiritual bastante comum, compartilhado por muitos. Se, entretanto, você sabe sem sombra de dúvida que está no Inferno, então, você deve estar na Via Expressa do Bronx!
\end{abstract}

Jeff Saltzman

Na seção V de Tudo que é sólido desmancha no ar: a aventura da modernidade, intitulada "Na Floresta dos Símbolos: algumas notas sobre o Modernismo em Nova York", o filósofo norte-americano Marshall Berman analisa as metamorfoses urbanas que aconteceram em meados do século XX em Nova Iorque. Ele começa a seção focalizando o trabalho de Robert Moses, o controverso planejador urbano que ajudou a redesenhar a paisagem de Nova Iorque à época. Moses foi responsável, entre muitas outras obras, pela construção da Via Expressa do Bronx, a qual mudaria para sempre não só o cenário do Bronx, mas também a vida de seus moradores.

Construída entre 1948 e 1963 como parte de uma rede de vias expressas cobrindo a área metropolitana de Nova Iorque, Nova Jérsei e Connecticut, e tida como a solução para os problemas do tráfego da cidade, a via expressa de 13,3 quilômetros de extensão teve repercussões tremendas nas vidas daqueles que viviam no Bronx (NEW YORK..., 2009, p. 1). Nascido em 1940, Marshall Berman recorda o impacto que a notícia da construção da via expressa teve para ele, que era na época um adolescente vivendo no Bronx:

Então, na primavera e no outono de 1953, Moses principiou a se agigantar sobre minha existência de uma nova maneira, com o anúncio de que estava a ponto de fincar uma imensa via expressa, de escala sem precedentes, custos e dificuldade de construção inéditos, no coração de nosso bairro. De início, não podíamos acreditar; aquilo parecia vir de outro mundo. Em primeiro lugar, quase nenhum de nós tinha um automóvel: o próprio distrito e 0 metrô que levavam ao centro da cidade definiam o fluxo de nossas vidas. Além disso, se a cidade precisava de uma estrada [...], eles com certeza não podiam estar dizendo o que as histórias pareciam contar: que a estrada seria dinamitada diretamente através de dezenas de quarteirões sólidos, estáveis, densamente povoados, como o nosso; que algo em torno de 60 mil pessoas, operários e gente de baixa classe média, sobretudo judeus, mas 
com muitos italianos, irlandeses e negros entre eles, seriam expulsos de seus lares. (BERMAN, 1986, p. 327)

Berman menciona dois aspectos da população do Bronx sobre os quais devemos refletir: primeiramente, eles eram majoritariamente da classe operária e da baixa classe média e poucos eram proprietários de automóveis. Aquela via expressa não estava sendo construída para facilitar a sua vida e para encurtar o seu tempo no trânsito. Ela estava sendo construída para beneficiar pessoas de fora do bairro e podemos supor que essas pessoas fossem de outra classe social, já que podiam ter seus próprios carros. Além disso, a população do Bronx era formada basicamente de minorias, como Berman a descreve. Portanto, pode-se imaginar se Moses teria sido bem sucedido na destruição do bairro, caso seus habitantes tivessem sido de outra classe e etnia. Em nome do progresso, pode-se perceber a existência de preconceito racial e social velado, embora Moses fosse ele mesmo judeu.

Se substituirmos as minorias citadas por Berman por latinos, principalmente de origem mexicana, poderíamos estar falando de East Los Angeles, área da cidade de Los Angeles que tem a maior população chicana do país e é, na verdade, a maior comunidade hispânica dos EUA (BENITEZ, 2004). Los Angeles viu a construção do Complexo de Vias Expressas de East Los Angeles - dentre outras vias expressas - mais ou menos ao mesmo tempo em que a Via Expressa do Bronx era construída em Nova Iorque.

De acordo com Los Angeles A to Z: An Encyclopedia of the City and County, escrita por Leonard e Dale Pitt, o sistema de vias expressas, o qual consiste de "vias de concreto, com quatro a seis pistas e sem cruzamentos" (PITT, 2000, p. 158; tradução minha), "unificou e definiu a estrutura física da área de Los Angeles desde a década de 1960. A região metropolitana, espalhada por uma grande área e descentralizada, tinha sido um dia descrita como ' 72 subúrbios em busca de uma cidade'." (PITT, 2000, p. 157; tradução minha). Desde a década de 1920, tinha se falado em criar um sistema de vias expressas, mas apenas em 1947 a criação de um sistema completo se tornaria possível graças ao aumento dos impostos e à disponibilidade de investimentos federais. A construção mais pesada, no entanto, só aconteceria nas décadas de 1960 e 70, quando a maioria das vias expressas planejadas originalmente estariam terminadas. Todavia, alguns dos planos originais jamais saíram do papel graças à pressão do público. As vias expressas nunca foram um consenso entre a opinião pública, nem em Nova Iorque, nem em Los Angeles (PIT'T, 2000, p. 158-161).

O Complexo de Vias Expressas de East Los Angeles é hoje o mais movimentado não só na cidade, mas em todo o mundo. Seis diferentes caminhos se formam pela interseção das Vias Expressas de Santa Mônica, Golden State, Pomona e Hollywood. Por elas passam todos os dias mais de quinhentos mil veículos. Considerado uma maravilha da engenharia à época de sua construção, assim como seu "primo" nova-iorquino, o complexo de East Los Angeles também foi responsável pelo deslocamento de inúmeras famílias locais, que tiveram que deixar suas casas da noite para o dia.

Em sua obra, a autora chicana Helena María Viramontes, nascida e criada em East L.A., retrata esse desenraizamento físico e emocional da população local depois da chegada das vias expressas. Seu mais recente romance, Their Dogs Came With Them, publicado nos EUA em 2007 e ainda sem tradução para o português, começa com Chavela, uma velha moradora da Rua Primeira em East L.A., fazendo as malas para se mu- 
dar. Ermila,conhecida como a menina Zumaya, que mora do outro lado da rua, observa Chavela etiquetando suas caixas em um inglês truncado, misturado com espanhol:

Fronhas repletas de objetos, encostadas na mesa de centro, etiquetadas pela velha mulher com palavras tão arranhadas que poderiam ter sido escritas pela mesma agulha usada para pregar as etiquetas às fronhas: cobijas, dizia uma etiqueta; Cosa del baño, dizia outra. No good dreses. Josie's typewriter. Fotos. (VIRAMONTES, 2007, p. 5; grifo da autora; tradução minha)

Ermila escuta a história da velha mulher sobre o terremoto que destruiu sua terra em sua juventude. A passagem termina com Chavela comparando o terremoto que causou seu primeiro deslocamento às escavadeiras responsáveis por seu atual deslocamento:

Preste atenção, Chavela ordenou. Porque deslocamentos sempre se resumirão a duas coisas: terremotos e escavadeiras. A criança olhava fixo para a fumaça do cigarro de Chavela subindo em espiral, tão grossa e visível como a fumaça negra do escapamento das escavadeiras pairando sobre o novo asfalto da Rua Primeira. Agora vá para casa! A velha mulher disse abruptamente, encaixotando um jogo de pratos enrolados em jornal. Pelo menos você tem uma. (VIRAMONTES, 2007, p. 8; tradução minha)

As escavadeiras mencionadas por Chavela e lembradas pela garota foram aquelas usadas para a construção das vias expressas do Complexo de East L.A. Elas se tornariam parte da paisagem da vizinhança enquanto as vias expressas eram construídas, incitando jogos infantis, como aquele jogado por Luis e Turtle, os "garotos Gamboa":

Luis convenceu Turtle a acreditar que eles poderiam alcançar um lugar chamado Novo México, onde se acorda batendo a cabeça no céu ou se tem polpa doce de cacto para o almoço ou se observa lagartos se transformando em jacarés à tarde. Para escapar, tudo o que eles dois teriam que fazer era cavar um túnel através do morro na Rua Leste, explicava Luis, e aquele país aguardava sua chegada. (VIRAMONTES, 2007, p. 25; tradução minha)

Entretanto, eles são flagrados por sua mãe e o "Novo México permaneceria uma região não descoberta e eles nunca saberiam o que era estar em outro lugar, ser outra pessoa." (VIRAMONTES, 2007, p. 26; tradução minha). É interessante ressaltar que a "terra prometida" das crianças é o Novo México e não Arizona ou Nevada, os quais são geograficamente mais próximos da Califórnia, refletindo certo desejo de retorno ao México, o qual as crianças nunca realizarão.

Do outro lado do país, Marshall Berman também descreve pungentemente como a presença das escavadeiras influenciou a rotina das crianças da vizinhança:

Por dez anos, do final dos nos 1950 ao início dos 60, o centro do Bronx foi martelado, dinamitado e derrubado. Meus amigos e eu ficaríamos sobre o parapeito da Grande Confluência, onde antes fora a 174th Street, e fiscalizaríamos o andamento das obras - as enormes escavadeiras e motoniveladoras, as estacas de madeira $\mathrm{e}$ de aço, as centenas de trabalhadores com seus capacetes de cores 
variadas, os gigantescos guindastes que se debruçavam bem acima dos telhados mais altos do Bronx, os tremores e as explosões provocados pela dinamite, as rochas recém-descobertas, ásperas e pontiagudas, os panoramas de desolação estendendo-se por quilômetros e quilômetros, até onde a vista pudesse alcançar, a leste e oeste - para nos maravilharmos ao ver nosso bairro comum e agradável transformado em sublimes, espetaculares ruínas. (BERMAN, 1986, p. 328)

Em "Neighbors", conto publicado no volume The moths and other stories em 1985 e também ainda sem tradução para o português, Viramontes nos traz outra representação literária do deslocamento que acompanhou a construção das vias expressas. O leitor pode ver as transformações na paisagem pelos olhos de um personagem de mais idade, Fierro, enquanto ele anda pela rampa de acesso à via expressa:

Ele ouviu as sirenes novamente, o tráfego rápido passando abaixo dele. Ele repentinamente se surpreendeu com como as coisas tinham mudado e como seria fácil esquecer que ali um dia tinham estado morros tranquilos, morros que ele trilhava até que eles foram removidos, dando lugar a terrenos baldios onde caminhos de terra se tornaram ruas e casas se tornaram lares. Então, a carta do governo chegou e todos foram forçados a sair, um a um, deixando para trás filas e filas de casas de madeira que rangiam com o inchaço da idade. Ele relembrava, enquanto observava e percebia o descuido com o qual os homens da empresa destruíam os casebres com vinte, trinta, quarenta anos de memórias, num espaço de meses. Como se isso não fosse suficiente, enormes buracos foram cavados para garantir que nenhuma raiz fosse deixada. A infinita via expressa pavimentou suas ruínas sagradas, seus segredos, seus túmulos, seu solo fértil no qual todas as memórias foram semeadas e esperavam a hora certa de florescer, e ele não podia fazer nada. (VIRAMONTES, 1995, p. ; tradução minha)

Em Their Dogs Came with Them, mencionado anteriormente, Chavela tem que se mudar. Felizmente, a casa dos avós de Ermila ficava do outro lado da rua, o lado que ficou de pé, "o lado vivo da Rua Primeira" (VIRAMONTES, 2007, p. 12; tradução minha), já que o projeto da via expressa destruíra apenas as casas de um lado da rua. Chavela não será mais vista no romance, a não ser nas memórias de alguns dos personagens, como na seguinte passagem, focalizada por Turtle:

[...] quando ela olhava da varanda de casa, como fazia agora, para a casa azul como todas as outras casas desaparecendo centímetro por centímetro, assim como Chavela e todos os outros vizinhos. Em seu lugar, o complexo de quatro vias expressas seria construído para redirecionar 547.300 carros por dia através do Eastside e se tornaria o mais movimentado da cidade. (VIRAMONTES, 2007, p. 169; tradução minha)

O isolamento dos que ficam é claro. Ermila tem uma nova "vizinha" que ela vê da janela de seu quarto: a via expressa. O capítulo dezessete, cujos acontecimentos se desenrolam por volta de dez anos mais tarde, começa com uma descrição da paisagem transformada: 
Um perpétuo nevoeiro letárgico de fumaça pairava sobre as rotas da via expressa. Divergência e convergência, seis vias expressas no quintal de Ermila, bem em frente à janela do seu quarto, embora ela raramente fizesse uso dos corredores delineados. Velocidade e caminhões, vans, motocicletas, arrancadas explosivas, trailers e mais carros, logo ali. Mas Ermila não conseguia, nem por um minuto, imaginar aonde ir se não direto para a cama. (VIRAMONTES, 2007, p. 313; tradução minha)

Esse pequeno trecho aponta para dois importantes aspectos. Em primeiro lugar, embora a garota tenha que ver as seis vias expressas de sua janela todos os dias, ela raramente as usa, assim como a Via Expressa do Bronx também não era útil para os habitantes do Bronx. A próxima passagem corrobora o sentimento de Ermila:

Quatro vias expressas cruzando-se, fazendo caracóis e empilhando-se no Eastside, mas se você não tinha um carro, você estava ferrado. Muitos estavam e isso era algo que Ermila sempre dizia para si mesma: Você está ferrada. Embora essa manhã ela tenha dito Nós estamos ferrados, conforme os homens passavam por sua janela para se juntarem na esquina para o ônibus Expresso 26, onde as mulheres já esperavam prontas. (VIRAMONTES, 2007 , p. 176; tradução minha, grifo meu)

Além disso, pode-se ver mais uma dimensão da destruição causada pela construção das vias expressas: ela destruiu não apenas as vidas dos que partiram e nunca mais foram vistos mas também daqueles que tiveram a "sorte" de ficar. Eles tiveram que conviver com o "perpétuo nevoeiro letárgico de fumaça" vindo das vias expressas, o qual prejudicava tanto sua saúde quanto a "saúde" do bairro. Em Tudo que é sólido desmancha no ar, Marshall Berman também reflete sobre os efeitos devastadores na Via Expressa do Bronx para sua vizinhança:

Na verdade, no momento em que a construção ficou pronta, a ruína real do Bronx simplesmente começava. Quilômetros e quilômetros de ruas ao lado da estrada sofreram o choque da poeira, dos gases e dos ruídos ensurdecedores - de modo mais notável o rugido dos caminhões de dimensão e potência nunca vistos no Bronx, rebocando pesadas cargas através da cidade, rumo a Long Island ou à Nova Inglaterra, a Nova Jérsei e a todos os pontos do Sul, durante o dia e a noite. Apartamentos que por vinte anos tinham sido seguros e estáveis foram esvaziados, muitas vezes virtualmente do dia para a noite. [...] então, despovoado, economicamente exaurido, emocionalmente em frangalhos (implacáveis como os danos físicos, as feridas interiores foram piores), o Bronx estava maduro para todas as terríveis espirais da praga urbana. (BERMAN, 1986, p. 328-329)

Muitos defensores da via expressa argumentam que o declínio do Bronx não foi causado somente pela construção da via e que ele teria acontecido com ou sem ela. Entretanto, o que é certo é que a deterioração do bairro veio imediatamente depois da construção da via expressa, conforme muitos de seus moradores mais bem sucedidos se mudaram para escapar dos problemas descritos acima por Berman e um novo grupo de moradores mais empobrecidos se estabeleceu ali, levando ao empobrecimento do Bronx. Berman afirma que 
[d]ez minutos nesta Estrada, um suplício para qualquer pessoa, são especialmente horríveis para aqueles que relembram o Bronx como costumava ser; que recordam essas cercanias como foram um dia, e vicejaram, antes que essa mesma estrada trespassasse seu coração e fizesse do Bronx, acima de tudo, um lugar do qual se quer sair. (BERMAN, 1986, p. 326)

Em East L.A., o impacto das vias expressas foi praticamente o mesmo. A ficção de Viramontes pinta um retrato perturbador do declínio do bairro e a deterioração no comportamento dos jovens. No segundo principal momento narrado em Their Dogs Came With Them, dez anos após a construção das vias expressas - portanto, no início dos anos 1970 - vemos uma vizinhança muito mais empobrecida, na qual os jogos infantis foram substituídos pelos "jogos" muito mais perigosos das gangues - os McBride Boys e os Lote M Homeboys. Alfonso, ou Big Al, namorado de Ermila, é o líder dos McBride Boys. Luis e Turtle são parte da gangue. Eles se juntam na noite para dirigir pela vizinhança e marcar seu território, pichando seus nomes nos muros. Os Lote Maravilla Homeboys são seus inimigos. Na passagem a seguir, depois que Turtle desertou da gangue, ela vaga sozinha pelas ruas à noite e lê a escrita nos muros, como se lesse uma profecia:

Ela sabia ler, Turtle não era burra. Os riscos, assinaturas e emblemas de novas gangues por cima das pichações dos McBrides nos muros da ponte - tudo más notícias. A gangue do Lote $M$ tinha desafiado os McBride Boys para um confronto classe-A completo. $[\ldots]$

Os vatos do Lote $\mathrm{M}$ falavam sério e gravavam grosseiramente por cima das assinaturas caligráficas - Alfonso aka Big Al, sir santos, Palo, Lucho Libre, Luis Lil Lizard, turtle, Mc Bride Boys Que rifa. Perfurando novos conquistadores por cima dos antigos com um martelo cego, as assinaturas que sobravam apagadas, cagadas, com golpes de tinta spray vermelha que escorria. Manchetes atrevidas, destemidas, Turtle pensava, olhando fixamente para o velho desenho de um lagarto de Luis, um rascunho para sua tatuagem, agora apagado por baixo das iniciais vermelhas da gangue do Lote $\mathrm{M}$. Aquilo era exatamente o que os vatos do Maravilla planejaram fazer na ponte, enviar um anúncio de apagamento. (VIRAMONTES, 2007, p. 217; tradução minha, grifo da autora)

Em outra passagem, a honestidade dos garotos é questionada por Salas, o dono da loja de carros local:

Alfonso ou Big Al era dono de um belo par de rodas, um Impala hidráulico de cor azul clara que ele tinha comprado do próprio Salas. Salas nunca perguntou como um rapaz tão jovem conseguira centenas de dólares tão amassados que as caras dos presidentes estavam enrugadas e cheias de veias. Não era seu papel como proprietário de uma loja de carros perguntar como um rapaz de dezenove anos, cuja assinatura revelava que ele não tinha passado do ginásio, podia tirar orgulhosamente diversas notas de uma carteira cheia e espalhá-las pelo balcão do caixa como uma mão de pôquer vencedora. (VIRAMONTES, 2007, p. 65; tradução minha) 
Em "Neighbors", o comportamento das gangues desempenha um papel ainda mais importante na história, a qual começa assim:

Aura Rodríguez sempre ficava dentro de seus perímetros, pessoais e de outras espécies, e esperava o mesmo de seus vizinhos. Ela estava bem ciente de que a vizinhança tinha lentamente se metamorfoseado em um cemitério, as pessoas de sua idade tinham morrido apenas para deixar seus netos com pouco conhecimento da luta. Como resultado, as crianças se juntavam perto de sua casa em pequenos grupos para beber, para se perderem no abismo da derrota, para encontrar consolo temporário uns nos outros. Ela compartilhava as mesmas ruas e lojas de esquina e meias-noites com esses jovens durões que jogavam latas de cerveja vazias em seu quintal [...].(VIRAMONTES, 1995, p. 109; tradução minha)

É interessante notar a ironia no fato de que Aura "sempre ficava dentro de seus perímetros" mesmo depois que as vias expressas foram construídas, com a intenção de abrir novos caminhos. Mais tarde, quando ela não consegue dormir por causa do barulho dos rapazes do lado de fora, ela tenta deliberar com eles e pede que eles voltem para casa. Entretanto, como tudo o que ela consegue é a resposta de que "eles estão em casa" e uma risada, ela decide chamar a polícia; ela se dá conta, no entanto, de que cometeu um enorme erro assim que a polícia chega:

Os cinco carros miraram no alvo, parando como tanques em um desenho animado. A polícia saiu em formação militar, pronta para o combate. [...] Quando os garotos estavam em fila, de braços e pernas abertos para a revista, Toastie tentou fugir, pulando por cima da cerca de ferro de Aura e caindo de cara na roseira. Com o rosto arranhado e sangrando, ele correu para a porta. [...] Quando os dois policiais arrastaram-no pelos degraus da varanda, ela podia ouvir o ranger de seus grossos cintos de couro contra suas balas. Ela começou a chorar. (VIRAMONTES, 1995, p. 115-116; tradução minha)

A polícia está, portanto, presente no bairro apenas para exercer seu poder repressivo. Eles se aproximam dos garotos com uma violência desproporcional às suas ações, o que, por sua vez, apenas gera mais violência por parte dos garotos contra a vizinha idosa. De certa maneira, o bairro está preso em um círculo vicioso do qual não será fácil sair. Aterrorizada pela ameaça dos garotos de que vão pegá-la, a história termina com Aura sentada em sua cadeira, segurando uma arma e apontando para a porta conforme alguém tenta abri-la.

De acordo com Carole Boyce Davies na introdução de Black Women, Writing and Identity, "[u]ma das jogadas finais dos conquistadores, depois da conquista, é a divisão dos territórios, criando fronteiras artificiais e, assim, levando a uma luta perpétua sobre o espaço e os lugares. Nesse contexto, invasões ganham um significado complexo" (DAVIES, 1994, p. 16; tradução minha). Tendo isso em mente, pode-se ler a construção das vias expressas como uma continuação da série de invasões sofrida pelo povo mexicano desde o século anterior. No século XIX, o governo dos EUA tinha criado uma fronteira artificial ao invadir o México e deixar uma parte considerável de sua população no lado agora norte-americano, tornando-os estrangeiros em seu próprio 
território. Por volta de cem anos depois, os chicanos de East L.A. sofreram outra invasão, a qual expulsou parte de sua população, redesenhou a geografia do bairro e mudou sua paisagem para sempre. Essa leitura é reiterada pela afirmação de Alicia Arrizón e Lillian Manzor de que latinos nos EUA "são tanto sujeitos pós-coloniais quanto neocoloniais: pós-colonialismo espanhol e neocolonialismo norte-americano". (ARRIZÓN; MANZOR, 2000, p. 12; tradução minha)

Neste ponto, podemos viajar de volta para o Bronx de Marshall Berman e evocar o seguinte trecho, no qual o autor analisa o papel do governo na proteção dos habitantes do Bronx contra a construção da via expressa:

E mesmo se [Robert Moses] tencionasse fazê-lo, tínhamos certeza de que tal não ocorreria aqui, não na América. Ainda nos aquecíamos ao crepúsculo do New Deal: o governo era nosso governo e acabaria por nos proteger no final. E, contudo, antes que nos déssemos conta, as escavadeiras mecânicas e as motoniveladoras haviam aparecido, e as pessoas recebiam os avisos de que era melhor saírem, e rápido. (BERMAN, 1986, p. 328; grifo do autor)

Aqui vê-se que o governo deles era deles apenas retoricamente. Quando era hora de escolher entre os direitos daquelas minorias que viviam no Bronx e dos moradores de origem anglo-saxã que precisavam da via expressa, os oficiais do governo não pensavam duas vezes. Igualmente, em East L.A., o governo neocolonial defendia o interesse dos moradores de origem anglo-saxã e deixava as minorias latinas em segundo lugar.

É interessante notar aqui que a Via Expressa de Long Beach, a qual deveria cortar South Pasadena, nunca saiu da planta. Moradores da área lutaram por décadas contra a via expressa, "argumentando que ela iria rachar ao meio uma antiga comunidade residencial e levar à destruição de muitas casas e vizinhanças históricas" (PITT, 2000 , p. 161; tradução minha). Nesse caso, a população foi ouvida pelo governo que interrompeu a construção. Não por acaso, South Pasadena é uma cidade de classe média, onde, de acordo com o censo de 2000 , por volta de $60 \%$ da população é branca. (CITY..., 2009)

Nem East L.A nem o Bronx tiveram o mesmo destino de South Pasadena. Mais de cinquenta anos após o início da construção das vias expressas, apenas muito recentemente os dois bairros começaram a se recuperar de seus efeitos, mas ainda há um longo caminho a ser trilhado. Suas populações foram permanentemente marcadas e provavelmente levará gerações para que seus habitantes sejam capazes de esquecer o calvário que essas construções trouxeram para suas vidas. De qualquer forma, os trabalhos de Marshall Berman e Helena María Viramontes estarão sempre aí para lembrar a eles e a nós aquilo que foi feito em nome do progresso.

\section{Referências bibliográficas}

ARRIZÓN, Alicia; MANZOR, Lillian. Introduction. In: Latinas on Stage. Berkeley: Third Woman Press, 2000. p. 10-20. 
BENITEZ, Tomas. "East L.A.: Past and Present". Disponível em: < http://www. pbs.org/americanfamily/eastla.html> . Acesso em: 18 Jan. 2009 (2004).

BERMAN, Marshall. Tudo que é sólido desmancha no ar: a aventura da modernidade. Tradução de Carlos Felipe Moisés e Ana Maria L. Ioriatti. São Paulo: Cia. das Letras, 1986.

CITY of South Pasadena. Disponível em: < http://www.ci.south-pasadena. ca.us/index.html>. Acesso em: 22 Fev. 2009.

DAVIES, Carol Boyce. Introduction: Migratory Subjectivies: Black Women's writing and the re-negotiation of identities. In: . Black Women, Writing and Identity: Migrations of the subject. London/New York: Routledge, 1994. p. 1-37.

NEW YORK City Roads. Disponível em: < http://www.nycroads.com/roads/> . Acesso em: 21 Fev. 2009.

PITT, Leonard; Dale. Los Angeles A to Z: An Encyclopedia of the City and Country. Berkeley/Los Angeles: University of California Press, 2000.

VIRAMONTES, Helena María. Neighbors. In: The moths and other stories. $2^{\mathrm{a}}$ ed. Houston: Arte Publico Press, 1995. p. 107-125.

. Their Dogs Came with Them. New York: Atria, 2007. 